\title{
Atelier paludisme: an international malaria training course held in Madagascar
}

\author{
Olivier Domarle ${ }^{1}$, Milijaona Randrianarivelojosia*1, Jean- \\ Bernard Duchemin ${ }^{1,2}$, Vincent Robert ${ }^{1,3}$ and Frédéric Ariey ${ }^{1,4}$
}

\author{
Address: ${ }^{1}$ Institut Pasteur de Madagascar, BP 1274, (101) Antananarivo, Madagascar, ${ }^{2}$ CERMES, BP 10887, Niamey, Niger, ${ }^{3}$ IRD, UR-16 Vecteurs, \\ and MNHN, USM-504 Biologie fonctionnelle des Protozoaires, Paris, France and ${ }^{4}$ Institut Pasteur du Cambodge, Phnom Penh, Cambodge \\ Email: Olivier Domarle - domarle.olivier@gmail.com; Milijaona Randrianarivelojosia* - milijaon@pasteur.mg; Jean- \\ Bernard Duchemin - duchemin@cermes.org; Vincent Robert - v.robert@mnhn.fr; Frédéric Ariey - fariey@pasteur-kh.org \\ * Corresponding author
}

Published: 9 May 2008

Malaria Journal 2008, 7:80 doi:10.1 186/1475-2875-7-80

This article is available from: http://www.malariajournal.com/content/7///80

(c) 2008 Domarle et al; licensee BioMed Central Ltd.

This is an Open Access article distributed under the terms of the Creative Commons Attribution License (http://creativecommons.org/licenses/by/2.0), which permits unrestricted use, distribution, and reproduction in any medium, provided the original work is properly cited.
Received: 10 March 2008

Accepted: 9 May 2008

\begin{abstract}
The Atelier Paludisme (Malaria Workshop) is an international training course organized by the Institut Pasteur de Madagascar, which has been held annually for the past five years. The course was designed for both young and experienced researchers, as well as for healthcare professionals, mostly from malaria-endemic countries. Its objective is to provide participants with a broad knowledge of all features of malaria, to improve their skills in project management, to break geographical isolation by using the Internet as a source of documentary information. This six-week course makes use of concepts of andragogy and problem-based learning, i.e. a relationship between participants and tutors, which promotes a process of exchange rather than the simple transmission of knowledge, where participants have to search actively for information. This approach to training, combined with the wide background and experience of those involved, creates positive dynamics and enables participants to acquire new skills, develop their critical and analytical abilities. This paper describes the course and the lessons learned from its evaluation.
\end{abstract}

\section{Background}

Malaria control programmes are based on several strategies, which work best when used in synergy. These strategies continually evolve as the result of technological advances, discovery of new tools, new drugs or new insecticides, as well as the results of innovative interventions carried out by experts. At country level, the efficacy of malaria control programmes depends on the establishment of coherent strategies, adapted to the specific needs of the country and with optimal use of limited resources.

For any strategy to be effective, the individuals involved need to have the best possible understanding not only of their own area of activity, but also of all the other technical disciplines involved in control programmes (e.g. diagnosis, treatment, epidemiology, entomology, education, communication, etc). In reality, at country-level, one finds that the various specialities involved in malaria control are often compartmentalized, and, even among decision-makers, knowledge of malaria is often limited and frequently out-of-date. The different actors, including clinicians, researchers and public health administrators, need to broaden their outlook beyond their own specialities in order to comprehend the problem as a whole. There are, currently, few courses that include the 'ability to 
comprehend the broader picture' as their main training objective.

The Atelier Paludisme, developed at the Institut Pasteur de Madagascar, makes use of original training methods, including problem-based learning techniques and encouraging participants to play an active role in their own training, under the supervision of experts.

\section{Organization of the workshop}

The general working principle of the Atelier Paludisme is to provide the participants with broadband internet access and enable them to find out about various aspects of malaria under the close supervision of international experts. The first week is devoted to practical sessions on improving computing skills and oral communication. Each of the following four weeks is organized around a major theme, and at the beginning of the week each participant is given a topic to research and expected, by the end of the week, to deliver a 10-minute presentation with power-point slides. The topics are selected in advance by the tutors, based on the topics covered each week and randomly distributed to the participants. Table 1 shows the overall course structure, including a selection of topics dealt-with by participants; full workshop content and participant presentations for the past five years can be found on the course web site [1]. The final week of the workshop is devoted to various forms of group work, including round table sessions and role-playing exercises. Practical sessions are organized at various times in the course of the workshop to illustrate technical issues (malaria diagnostic, geographical information systems, entomology).

\section{Tutors and participants}

In addition to course organizers, the teaching faculty consists of a group of 10-15 invited experts, who act as tutors to the participants. Each tutor stays with the course for one week (two or three tutors per week). The role of tutors is to guide the participants in their search for information on the internet, to help them to critically evaluate the

Table I: Breakdown of the programme

\begin{tabular}{lr}
\hline Domains and situations & Number of hours \\
\hline Practical sessions & $60 \mathrm{~h}$ \\
Presentations by tutors & $30 \mathrm{~h}$ \\
Presentations by participants & $36 \mathrm{~h}$ \\
• Group work & $82 \mathrm{~h}$ \\
- Individual work & $32 \mathrm{~h}$ \\
• Presentations & $16 \mathrm{~h}$ \\
• Assessment and individual evaluation & $\mathbf{2 5 6 ~ h}$ \\
\hline TOTAL & \\
\hline
\end{tabular}

Details concerning the timetable for this course are published on the course website [I]. information found and to make sure that their presentation is accurate (in order to avoid exposing the other participants to presentations containing erroneous information or misunderstandings).

Each tutor is asked to give a 50-minute lecture on a topic of their choice, usually their own research, and the lectures are followed by an open discussion with participants, course faculty and guests. These lectures by tutors represent the only formal teaching of the course and they represent only $10 \%$ of the overall contact time of about 256 hours.

At the end of each week, when participants give their 10minute presentation, tutors and course organizers act together as a panel of examiners to evaluate the work and the presentation in a deliberately formal manner (Figure 1), using an evaluation grid including 20 criteria related to the form and content of the presentation, scored on a fivepoint scale (from "not acquired" to "completely mastered"). The scores awarded are used to construct a histogram providing a visual indication of the overall quality of the presentation and making it possible to identify strengths and weaknesses and to assess the progress made (Figure 2). The weekly cycle ends with an individual interview between each participant and the tutors for that week to identifying what the participant has learned and his/her weaknesses.

During the annual sessions from 2003 to 2007, 76 participants from 15 different countries were trained at the Atelier Paludisme. From the beginning, the intention was to

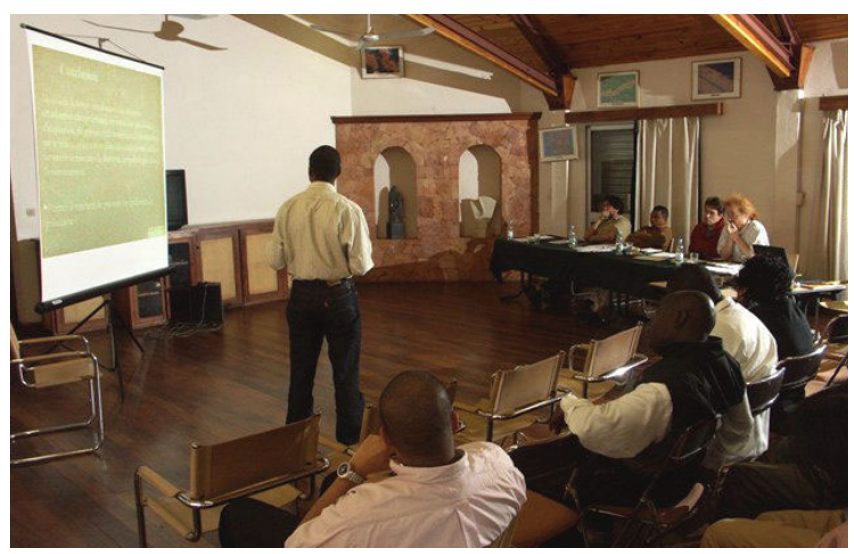

Figure I

Presentations to the panel. Footnote: The presentations are given at the end of the week, in front of the other participants and the panel, composed of tutors. These sessions allow the participants to demonstrate their acquisitions, by defending their approach, and aim to evaluate the work done during the week (Photo: courtesy of Dr Olivier Domarle, Atelier Paludisme 2006). 


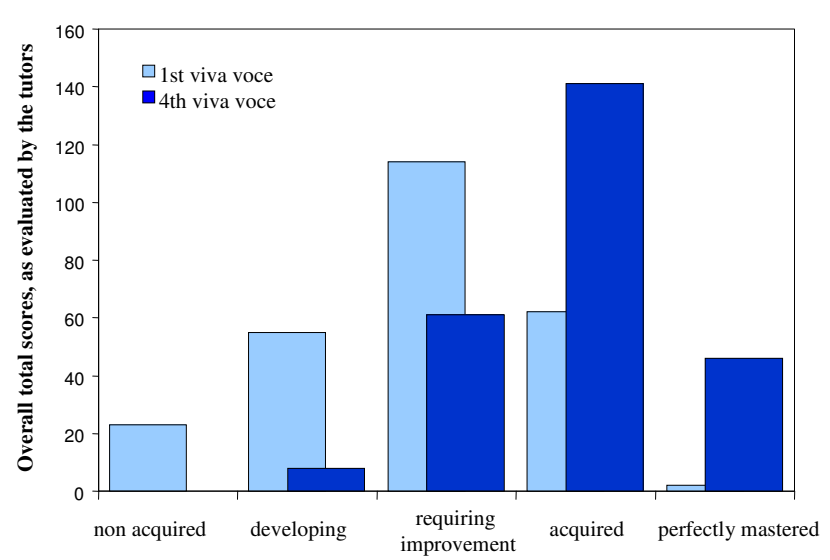

Figure 2

Comparison of evaluations for the first and fourth presentations. Footnote: Cumulative scores for all evaluation criteria are shown on the y axis. Atelier Paludisme 2003; I3 participants.

achieve a good mix of participants: 1/3 clinicians, 1/3 public health administrators (i.e. scientists or health professionals involved in malaria control at national or regional level, usually employed by their Ministry of Health) and $1 / 3$ research scientists (either at PhD student or post-doctoral level). Over the five-year period, this optimal ratio was more or less achieved. As the course was held in Madagascar, it is not surprising that $60 \%$ of its participants were from Madagascar for the first course in 2003 , but this was reduced to $25 \%$ by 2007 . As the course became increasingly well-known, the number of applicants gradually increased and so did the geographical diversity of participants with 11 different nationalities in 2007 (Figure 3).

\section{Evaluation and follow-up}

Both tutors and participants were asked to evaluate the training, and their comments and suggestions were used to improve the workshop from one year to the next. An external audit of the five first sessions of the workshop was carried out in 2007, based on theoretical educational concepts. The design of this training was considered appropriate to its aims, particularly with respect to the acquisition of transverse skills, the use of appropriate learning models, the phases of knowledge acquisition, the identification of problems to be solved, material aspects, the availability of the tutors during the workshop, exchanges of experience between participants and tutors and the self-confidence acquired, especially when giving presentations. The preparation and delivery of presentations, and online bibliographical searches were considered important skills that the participants will be able to use in their professional lives, whatever their future post. The audit identified the following weak points, including

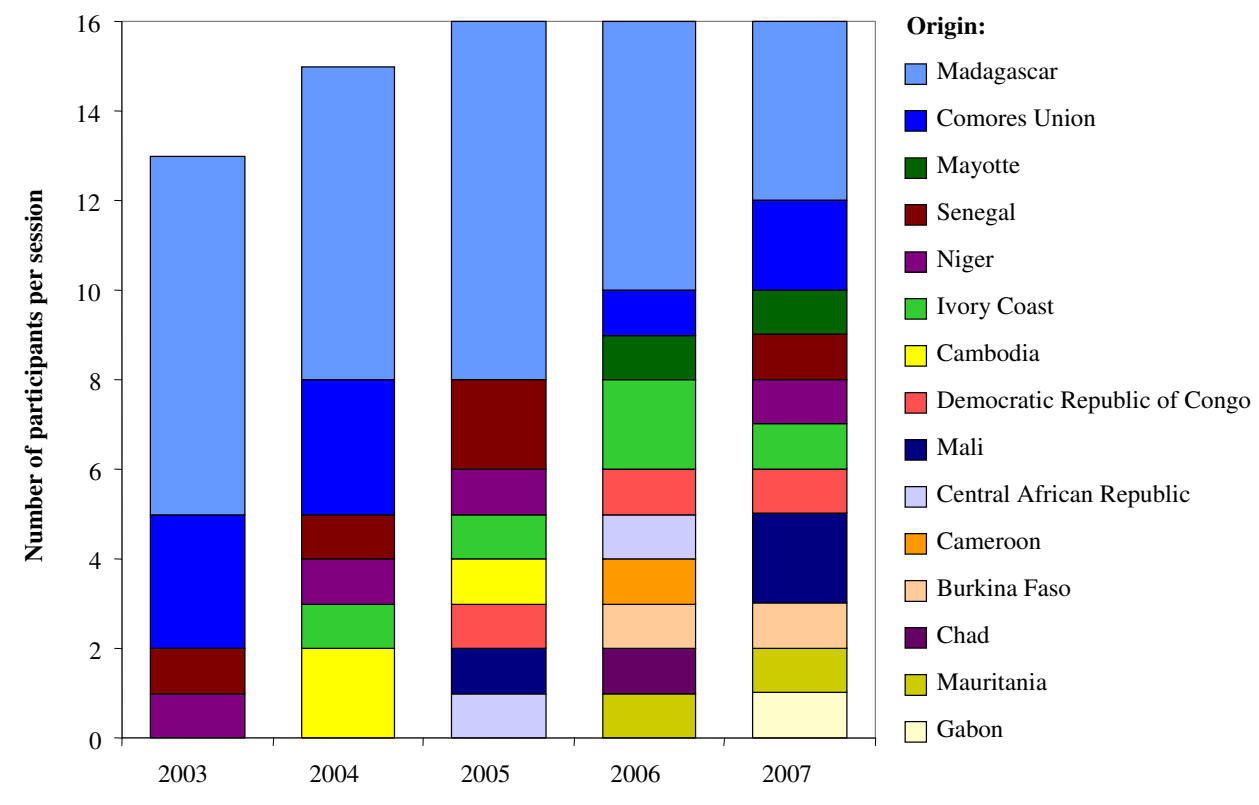

Figure 3

Origin of the participants for the Atelier Paludisme sessions held in 2003-2007. Footnote: The dissemination of information has led to an increase every year in the number and diversity of applicants. This increase has led to greater selection of applicants. 
Table 2: Follow-up of former participants and comparison with matched controls.

\begin{tabular}{|c|c|c|}
\hline & Former participants & Matched colleagues \\
\hline Responses & $41 / 60(68 \%)$ & 19 \\
\hline \multicolumn{3}{|l|}{ Speciality: } \\
\hline Doctor & $46.3 \%(19 / 41)$ & $53.6 \%(10 / 19)$ \\
\hline Entomologist & $12.2 \%(5 / 41)$ & $15.8 \%(3 / 19)$ \\
\hline Participant researcher & $14.6 \%(5 / 4 \mid)$ & $15.8 \%(3 / 19)$ \\
\hline Pharmacist & $7.3 \%(3 / 41)$ & \\
\hline Specialist technician & $4.9 \%(2 / 4 I)$ & $5.3 \%(1 / 19)$ \\
\hline Lecturer-researcher & $4.9 \%(2 / 4 I)$ & \\
\hline Other & $9.8 \%(4 / 4 I)$ & $10.5 \%(2 / 19)$ \\
\hline Better able to assume functions since the training & Yes for $88 \%(36 / 41)$ & - \\
\hline Better able to give presentations & Yes for $73 \%(30 / 41)$ & Yes for $58 \%$ (11/19) \\
\hline Better able to train others & Yes for $80 \%(33 / 41)$ & Yes for $68 \%(13 / 19)$ \\
\hline Better professional relations since the training & Yes for $85 \%(35 / 4 I)$ & - \\
\hline Development of new activities since the training & Yes for $80 \%(33 / 4 I)$ & - \\
\hline \multicolumn{3}{|l|}{ Development of a project as: } \\
\hline Principal investigator & Yes for $34 \%(|4 / 4|)$ & Yes for $37 \%(7 / 19)$ \\
\hline Collaborator & Yes for $68 \%(28 / 41)$ & Yes for $68 \%(13 / 19)$ \\
\hline \multicolumn{3}{|l|}{ Obtained funding as: } \\
\hline Principal investigator & Yes for $20 \%(8 / 41)$ & Yes for $21 \%(4 / 19)$ \\
\hline Collaborator & Yes for $44 \%$ (I8/4I) & Yes for $37 \%$ (7/19) \\
\hline Training has helped with grant applications and obtaining funding & Yes for $63 \%(26 / 41)$ & - \\
\hline Change in professional activities since the training (as assessed by third party/superior) & Yes for $78 \%(32 / 41)$ & - \\
\hline
\end{tabular}

The survey of matched controls included colleagues of former participants. The questionnaires were distributed, by the former participants, to colleagues with similar training, in a similar post, dealing with malaria, tuberculosis or AIDS.

a tendency to information overload, due to intensive weekly cycles preventing adequate consolidation of the knowledge acquired. This external viewpoint will be taken into account to improve future workshops.

In order to evaluate the long-term impact of the workshop, a follow-up of former participants was performed through annual questionnaires, to find out what impact the training had on their professional activities. In the 2007 survey, targeting participants having attended the first four sessions of the workshop, $68 \%$ (41/60) of participants responded. An overview of the responses of former participants and matched controls (who had attended different training courses in other subjects) is provided on Table 2. The subjective criteria recorded by former participants (improvements in their ability to assume their functions, strengthening of professional relationships) are positive, although one cannot exclude a bias in these responses.

\section{Funding}

The annual budget was approximately $€ 80,000$, covering the full costs for 15 to 16 participants and 10 to 15 invited tutors. It was considered essential to cover the cost for participants in order to be able to select them not on financial criteria, but on pertinent criteria such as past experience, country of origin, present involvement in malaria research or control. The Réseau International des Instituts Pasteur (the Institut Pasteur International Network) and Impact Malaria/Sanofi-Aventis have covered a large portion of this budget, with contributions from the Institut Pasteur de Madagascar, the Institut de Recherche pour le Développement, a French Overseas Development grant, the Direction des Affaires Sanitaires et Sociales de Mayotte, the World Bank, the WHO/Roll Back Malaria programme, the Agence Universitaire de la Francophonie and private partners (Fondation Mérieux, Natixis, Medical International and Technikon). This mixed funding reflects the variety of stakeholders needed for such a course and is important for its long-term viability.

\section{Conclusion}

The Atelier Paludisme is currently one of the few courses to give a broad working knowledge of malaria and, as such, it meets the training needs of healthcare personnel involved in malaria research and control, enabling them to remain up-to-date with recent developments in the field. Because it focuses less on content and more on the resolution of problems and information finding, it contributes to honing the professional skills of participants. The Atelier Paludisme has recently been accepted as a module in the new mastère spécialisé de l'École Pasteur/CNAM de santé publique [2] and, since 2007, a sister-course in English is now run in Tanzania, as a collaboration between Institut Pasteur, the Swiss Tropical Institute and the Tanzanian Centre for International Training in Ifakara [3]. An 
expanded version of this paper was recently published in French [4].

\section{Authors' contributions}

$\mathrm{OD}, \mathrm{MR}, \mathrm{JBD}, \mathrm{VR}$ and FA were involved in initiating the Atelier Paludisme. All authors read and approved the final manuscript.

\section{Acknowledgements}

The Atelier Paludisme has been run under the auspices of the Ministry of Health, Family Planning and Social Protection of Madagascar. The Minister of Health himself has often honoured us with his presence. We thank those who have provided us with funding and support and who have shown us continuing interest and confidence. We also thank all those who have participated at the Atelier Paludisme: the participants and tutors for their availability and for investing so much in their functions by adhering fully to this training approach. We especially thank Prof Marcel Hommel, who actively helped us with the design, setting-up, running and maintenance of this training. The Atelier Paludisme is organized through collaboration between different units within the Institut Pasteur de Madagascar. The external audit was carried out by ASFOR, a company specializing in training, recruitment, auditing and consultancy at Antananarivo, Madagascar. We are grateful to the Editor-in-Chief of Médecine Tropicale for allowing us to publish this commentary.

\section{References}

I. Institut Pasteur de Madagascar: Atelier Paludisme de I'Institut Pasteur de Madagascar. [http://www.pasteur.mg/Atelier-Palu/].

2. CNAM/Pasteur: Mastère spécialisé de santé publique de l'école Pasteur/CNAM de santé publique. [http://www.cnam.fr/pas teur].

3. Tanzanian Training Centre for International Health: Capacity building in malaria with a focus on e-learning in Ifakara, Tanzania. [http://healthtrainingifakara.org/Malaria.Course2007.html].

4. Domarle O, Randrianarivelojosia M, Duchemin JB, Robert V, Ariey F, Hommel M: Formation francophone sud/sud: I'Atelier Paludisme de I'Institut Pasteur de Madagascar. Med Trop 2007, 67:505-512.

\section{Publish with Bio Med Central and every scientist can read your work free of charge}

"BioMed Central will be the most significant development for disseminating the results of biomedical research in our lifetime. "

Sir Paul Nurse, Cancer Research UK

Your research papers will be:

- available free of charge to the entire biomedical community

- peer reviewed and published immediately upon acceptance

- cited in PubMed and archived on PubMed Central

- yours - you keep the copyright

Submit your manuscript here:

http://www.biomedcentral.com/info/publishing_adv.asp 